\title{
Thyrotoxic Cardiomyopathy: A Study of Three Cases
}

\author{
Adegbenga B Ademolu* \\ Department of Medicine, Lagos State University Teaching Hospital, Nigeria
}

*Corresponding author: Ademolu AB, Department of Medicine, Lagos State University Teaching Hospital, Ikeja, Lagos, Nigeria

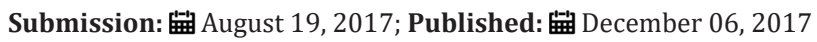

\begin{abstract}
A 49 years old Nigerian female presents with breathlessness, pedal swelling, orthopnea, paroxysmal nocturnal dyspnea (PND) and palpitation. She had a goiter. Her EKG result showed atrial fibrillation. A 27 year old Nigerian female with Grave's disease diagnosed 10 months prior to presentation presented with breathlessness, palpitation, orthopnea and PND. She was previously treated with carbimazole and propranolol with poor compliance. A 55 year old Nigerian female presented with breathlessness, orthopnea and PND. She had a history of a goiter 30 years earlier which regressed. Thyrotoxic heart disease can present with arrhythmia or dilated cardiomyopathy.
\end{abstract}

Keywords: Thyrotoxicosis; Cardiomyopathy; Arrhythmia

\section{Introduction}

Thyrotoxic cardiomyopathy (TCMP) defines a myocardial damage caused by the toxic effect of abundant thyroid hormones (TH) that result in altered energy production by myocytes (oxidative phosphorylation glycolysis) intracellular metabolism (protein synthesis) and myofibril contractile function [1,2]. Epidermiologic data on TCMP is currently lacking worldwide.

The main manifestation of thyrotoxic cardiomyopathy (TCMP) are left ventricular hypertrophy (LVH), [3,4] arrhythmias (usually atrial fibrillation), dilation of heart chambers and heart failure, pulmonary hypertension and diastolic dysfunction.

Thyrotoxic heart disease encompasses cardiac symptoms signs and pathophysiologic impairment due to over activity of the thyroid gland usually due to excessive sympathetic stimulation. Thyrotoxic heart disease is a potentially treatable cause of morbidity and mortality. Cardiac symptoms have been elicited in as much as $33 \%$ of patients with hyperthyroidism $[5,6]$ of these $57 \%$ had preexisting ischaemia, hypertensive or valvular heart disease [5,6].

In sub Saharan Africa the incidence of thyrotoxic heart disease ranges from $6.2-8 \%$ [7-9]. In Nigeria an incidence rate of $27 \%$ was reported [10] with a male: female ratio of 1:5 [10]. Thyrocardiac disease is an uncharted territory in Nigeria and data on thyrocardiac disease are scanty. I present three cases of thyrotoxic cardiomyopathy to highlight the importance of thyrotoxicosis as an important cause of heart failure in our practice. The aim of this study is to report the clinical course of thyrotoxic cardiomyopathy in 3 patients.

\section{Cases}

\section{Case One}

Mrs. GC was a 49 years old Nigerian trader presenting with two weeks history of breathlessness, one week history of pedal swelling and four day history of cough. Her breathlessness started on exertion and was relieved by rest, there was associated poorly radiating dull central chest pain with no aggravating or relieving factor, there is associated orthopnea, paroxysmal nocturnal dyspnea and palpitation. Bilateral pedal swelling started a week prior to presentation it has been recurrent with polyuria and bilateral loin pain no dysuria, no nocturia, no frothiness of urine, no facial swelling that regresses as day goes by. Dry cough started four day prior to presentation with associated low grade fever, occasional polydipsia no polyphagia. She has been having chronic diarrhoea and weight loss for one year with human immunodeficiency virus test that is negative repeatedly.

Diagnosed to have peptic ulcer disease two years ago, not a known hypertensive, diabetic or thyrotoxic patient. She is married to a 55 year old Nigerian clergyman with four children. She doesn't smoke or take alcohol.

On examination she was cachectic, afebrile ,pale, slightly icteric, not cyanosed, no asterixis, bilateral pitting pedal oedema up to the knee, fine tremor present, World Health Organisation (WHO) stage $1 \mathrm{l}$ goitre, measures $8 \mathrm{~cm} \times 4 \mathrm{~cm} \times 1 \mathrm{~cm}$ no eye signs. Cardiovascular examination showed pulse rate 120 beats/min, arterial wall thickened, irregularly irregular, locomotor brachialis, 
blood pressure was $157 / 102$, jugular venous pressure (JVP) was raised to angle of the jaw; left parasternal heave was present with apex beat at 6th left intercostal space lateral to mid clavicular line (6LICSLMCL) with S1S2S3 gallop rhythm. She had hepatomegaly of $10 \mathrm{~cm}$ below right costal margin, mildly tender, surface is smooth and there is mild ascites. She had fine basal crepitation on the lung bases.

Her electrocardiographic result shows ventricular rate 146 beats/min, irregular R-R interval, ventricular premature complexes, T-wave changes in anterolateral leads and atrial fibrillation. Her thyroid function test showed free T3 $18.59 \mathrm{pg} / \mathrm{ml}$ (normal 2.5$3.9 \mathrm{pg} / \mathrm{ml}$ ), free T4 $4.17 \mathrm{ng} / \mathrm{dl}$ (normal 0.58-1.64ng/dl) Thyroid Stimulating Hormone (TSH) $0.61 \mathrm{uIU} / \mathrm{ml}$ (normal 0.34-5.6uIU/ $\mathrm{ml}$ ). Her electrolyte and urea showed normal sodium, potassium, chloride, bicarbonate, and urea, her creatinine was elevated 394umol/litre (normal 53-115umol/litre). Her total serum calcium was normal. She was managed as a case of congestive cardiac failure secondary to thyrocardiac disease precipitated by atrial fibrillation. She was placed on subcutaneous clexane $40 \mathrm{mg}$ 12 hourly, intravenous frusemide $100 \mathrm{mg} 8$ hourly for 16 hours then 60mg 12 hourly, intravenous amoxicillin+ clavulanic acid $1.2 \mathrm{~g} 8$ hourly, oral carvedilol $3.125 \mathrm{~g}$ twice daily, Digoxin $0.125 \mathrm{mg}$ daily, Candesartan $4 \mathrm{mg}$ daily, aspirin $75 \mathrm{mg}$ daily, aldactone $25 \mathrm{mg}$ twice daily , carbimazole $15 \mathrm{mg}$ thrice daily and propranolol $40 \mathrm{mg}$ daily. She could not complete investigation like echocardiography however she improved significantly clinically and was later discharged on request due to financial constraint.

\section{Case two}

Miss KG was a 27 year old Nigerian with Graves' disease diagnosed ten months prior to presentation who presented with breathlessness of three days duration which occurred at rest on exposure to smoke with associated palpitation, orthopnea, paroxysmal nocturnal dyspnea and oedema. She had prior history of breathlessness which is not triggered by exposure to dust, cold or animal fur, she is not asthmatic. Cough productive of yellowish sputum started at the same time associated with pleuritic chest pain, low grade fever, headache, polydipsia and polyphagia.

No previous history of loss of consciousness, irrational talk nor polyuria. She was on oral carbimazole and propranolol. She stopped using propranolol a month before presentation and the carbimazole she was on had expired a month earlier. No history of drug allergy, she is single, an undergraduate studying philosophy she doesn't use alcohol nor smoke.

On examination: she was febrile with mild pedal oedema and WHO grade 111 goitre, she had proptosis, lid lag and lid retraction, weight $73 \mathrm{~kg}$, height $1.64 \mathrm{~m}$, waist circumference $89 \mathrm{~cm}$ hip circumference $110 \mathrm{~cm}$ and waist/hip ratio 0.80 . Cardiovascular examination reveals pulse rate 96 beats/min, blood pressure $110 / 70 \mathrm{mmHg}$ Jugular venous pressure was raised , apex beat was at 6LICSMCL, S1 S2 only Respiratory system reveals tachypnea respiratory rate $25 \mathrm{cycle} / \mathrm{min}$ with widespread coarse crepitation in the middle and lower zone posteriorly.
No significant finding in the abdomen and central nervous system. She was managed as a case of thyrotoxicosis with

1) Thyrotoxic heart disease with imminent heart failure,

2) Chest infection and

3) Thyroid ophthalmopathy.

She thereafter became stable and was discharged a week after presentation. Due to financial constraint necessary investigation could not be done. She was lost to follow up.

\section{Case three}

Mrs. OA was a 55 year old Nigerian working as a teacher who presented with two months history of breathlessness which occurred during domestic work and progressed to breathlessness at rest with associated two pillow orthopnea, paroxysmal norturnal dyspnea with no cough. Palpitation started at the same time, it was not precipitated by drug, no previous history of palpitation, but was diagnosed hypertensive 15 years ago and was on oral aldomet $250 \mathrm{mg}$ daily and moduretic one alternate day. She had a low grade fever associated with anorexia vomiting and abdominal pain with polydipsia, no polyphagia, no polyuria. Her condition progressed and was noticed to have anterior neck swelling two months into the illness. She had similar anterior neck swelling 30years earlier as a primigravida, but the goiter regressed during puerperium, there was no goitre in subsequent pregnancy; she is para 4+0 (5 alive). Her mother sister and an aunt all had goitre. She is separated from her husband with whom she had 5 children she hails from ibonwo near Epe in Lagos state Nigeria. She doesn't smoke nor use alcohol.

On examination, she had WHO grade 11 goitre with lid lag and lid retraction. Cardiovascular system revealed pulse rate $92 \mathrm{~b} / \mathrm{min}$, blood pressure $120 / 60 \mathrm{mmHg}$, JVP not raised; apex beat was at 5LICS lateral to mid clavicular line. All other systems were essentially normal. Her thyroid function test showed low thyroid stimulating hormone with elevated triiodothyronine and tetraiodothyronine. She is yet to do other investigations. She was managed as a case of thyrotoxic heart disease and is presently being followed up.

\section{Discussion}

In Nigeria today, thyroid disorders remain a common endocrine disorder with diverse metabolic sequela. Thyrotoxic heart disease can present with sinus tachycardia, systemic hypertension, arrhythmia or cardiomyopathy, dilated cardiomyopathy being the most reported in thyrotoxics [11].

Tachycardia in thyrotoxicosis develops due to the faster diastolic depolarization associated with the shortening of action potential of the sinoatrial node cells [12]. The pathogenesis and mechanism of arrhythmogenesis in thyrotoxicosis has been ascribe to influence of thyroid hormone on myocardium, increased sympathetic activity and reduced intracellular potassium.

Case one had T3 more than four times upper limit of normal and T4 almost three times upper limit though with TSH in lower limits of normal. She had multiple complication of thyrotoxic 
cardiomyopathy like tachycardia, cardiomegaly with atrial fibrillation. Her ventricular premature complexes may be a pointer to the severity of her thyrotoxicosis which has hitherto progressed silently before diagnosis on presentation. The four fold rise in T3 and almost three fold rises in T4 coupled with the multiplicity of complication of thyrotoxic heart disease suggest that more studies need to be done to correlate the level of thyroid hormone excess to severity of thyrotoxic cardiomyopathy.

The incidence of cardiac arrhythmia in thyrotoxicosis varies in a wide range. Sinus tachycardia is the most common occurring in 42$73 \%$ of cases [11]. Elevated resting heart rates are associated with higher mortality. Sinus bradycardia is rather rare in thyrotoxicosis. Atrial fibrillation takes second place among cardiac arrhythmia occurring in $9-23 \%$ of thyrotoxics compared to $0.4-1.0 \%$ in general population [11]. It is the most common cardiovascular complication of thyrotoxicosis and is associated with high morbidity and mortality related to thromboembolism [11]

This patient was on carbimazole and propranolol with poor drug compliance. Now carbimazole is an anti thyroid pro drug that gets converted to methimazole the active metabolite which act by inhibiting synthesis of thyroid hormone by blocking oxidation of iodine in thyroid gland, it blocks synthesis of thyroxine T4 and triiodothyronine $\mathrm{T}$, in this patient, the poor drug compliance would have caused more synthesis of T4 and T3 with the resultant cardiotoxic effect on the myocardium due to excessive cardiac myocyte exposure, the fact that she had clinical features of thyrotoxic cardiomyopathy was in support of this, however, her not carring out her investigation makes the biochemical evidence of excessive T4 and T3 to be unavailable, however the clinical evidence were glaring.

Propanolol is a non-cardioselective sympatholytic beta blocker that crosses the blood-brain barrier. It blocks the action of epinephrine and norepinephrine in beta 1 and beta 2 adrenergic receptors, it also has a membrane stabilizing effects, again her clinical features suggest this effect were lacking as her pulse rate was 96 beats per minutes which was in upper limits of normal and she also had palpitation which could be reduced or removed by propranolol, however her non compliance made this not possible in her.

Case 2 had thyrotoxic heart disease (dilated cardiomyopathy) at a young age, this finding have been documented in previous studies [10]. In this patient poor drug compliance and use of expired drug tilted her to a state of imminent heart failure before the arrest of progression by way of admission and appropriate therapy. This raises the question that what factors could predispose a thyrotoxic to developing thyrotoxic heart disease instead of other complications of thyrotoxicosis? Could it be genetic, socioeconomic or environmental factors? There is need to explore this area by way of scientific studies.

Socioeconomic factors have a role in the diagnosis and management of thyrotoxic heart disease. Miss KG as a low socioeconomic undergraduate of philosophy could not afford her investigation like electrocardiography, echocardiography and repeat thyroid function test, also her low economic power could have been a reason for discontinuing propranolol a month prior to presentation. This throws a surmountable challenge to the three tiers of governments and nongovernmental organization in our nation to consider a free diagnosis and management programme for persons living with thyrotoxic heart disease like HIV patients in tertiary centers. If such programme is possible for HIV patients then why not for thyrotoxic heart disease patients who are perhaps a smaller proportion of our ever increasing population.

Subclinical thyrotoxicosis is associated with the increased risk of atrial fibrillation. In the Framingham study at 20 years follow up, the incidence of AF was $25 \%$ in patients with low TSH that is 3 times as high as in euthyroid state with incidence of 7\% [11]. The prevalence of $\mathrm{AF}$ seems to be comparable in overt and subclinical thyrotoxicosis. Extrasystoles 5-7\%,paroxysmal tachycardia $0.2-3.3 \%$ and atrial flutter approximately $1.4 \%$ rarely occurs in thyrotoxicosis.24-hours EKG monitoring demonstrate that Atrial arrhythmia are typical for thyrotoxicosis while ventricular arrthythmias occurs only in severe cases [11] and in subjects with concomitant cardiovascular disease.

Case 3 is an elderly thyrotoxic with thyrotoxic heart disease, she could have had a subclinical or silent thyrotoxicosis within the 30years of her first goiter and the current one and this may account for her displaced apex beat and hypertension. Though her hypertension could also be primary. Her case emphasises the need for a long term follow up in patients with regressed goiter in order to prevent a resultant complication like thyrotoxic cardiomyopathy.

The presence of palpitation in all three cases and pulse rate in high level of normal or a tachycardia justifies the need for beta adrenergic blockade in these patients which was done. The enlargement of cardiac silhouette in thyrotoxic cardiomyopathy varies as seen in these three cases, while two cases had cardiac enlargement to the sixth intercostals spaces one was minimally enlarged in the fifth intercostals space to the lateral side of the midclavicular line, whether the degree of cardiac enlargement can be correlated to the blood levels of T4 and T3 in blacks and other races is a study worth looking into in the near future.

Dilated thyrotoxic cardiomyopathy occurs in $1 \%$ of thyrotoxics and one thirds of cases is irreversible [11]. In a future study it will be needful to study thyrotoxic cardiomyopathy and hypoglycaemia and describe the grade of hypoglycaemia commonly seen in thyrotoxic cardiomyopathy compared to the general population worldwide and in different races and ethnic group [13]. The prevalence of mitral valve prolapse in thyrotoxicosis is $18-41 \%$ compared to $6-20 \%$ in general population [11]. Since the incidence of thyrotoxic heart disease in nigeria is $27 \%$ while in sub Saharan Africa is $6.2-8 \%$, then we should seek to answer questions like why are Nigerians coming down with thyrotoxic heart disease than their sub Saharan counterparts? And is the incidence increasing or on the decline and is the incidence the same in all the six geopolitical zones of our country? A nationwide multicenter study may be the answer. 


\section{Conclusion}

Thyrotoxic heart disease can affect both the young and elderly patients with thyrotoxicosis [14-18]. It can be associated with very high levels of thyroid hormones (both T3 and T4), it can also present with multiple cardiovascular complication. A high index of suspicion should be entertained for this all important complication of thyrotoxicosis among Nigerians.

\section{References}

1. (1996) World Health Organisation/International Society and federation of cardiology Task Force on the definition and Classification of Cardiomyopathy. Circulation 93: 841842.

2. Klein l (1990) Thyroid hormone and the cardiovascular system. Am J of Med 88(6): 631-637.

3. Ching G, Franklyn JA, Stallard TJ, Daykin J, Sheppard MC, et al. (1996) Cardiac hypertrophy as a result of long-term thyroxine therapy and thyrotoxicosis. Heart 75(4): 363-368.

4. Dorr M, Wolff B, Robinson DM, John U, Lüdemann J, et al. (2005) The association of thyroid function with cardiac mass and left ventricular hypertrophy. J Clin Endocrinol Metab 90(2): 673-677.

5. Sandler G, Wilson GM (1959) The nature and prognosis of heart disease in thyrotoxicosis. Q J Med 28: 247-269.

6. Robin PC, John MacDermot (1998) Heart failure in thyrotoxicosis, an approach to management. Br J Clin Pharmacol 46(5): 421-424.

7. Famuyiwa 00 (1987) Cardiac disease in Nigerians with thyrotoxicosis. Tropical Cardiology 13: 15.
8. Olurin EO, Itayemi SO, Oluwasanmi Jo, Ajayi OO (1973) The pattern of thyroid gland diseases in Ibadan, Nigeria. Nigerian Med J 3: 58-65.

9. Nkoua JL, Mbam B, Bandoho MA, Aba G, Bouramoue CH, et al. (2000) Thyrotoxic heart disease; incidence, causes and clinical characteristics. A review of 20 cases. La Sante Tropicale sur Internet. Medicine d'Afrique Noire. Tome 47.

10. Ogbera Ao, Fasanmade O, lsiba A (2007) The scope o f cardiac complications of thyrotoxicosis in Lagos, Nigeria. Pak J Med Sci (Part-I) 23(5): 671-675.

11. Alina YU, Alekbar AB, Elena NG, Eugenia OU (2012) Thyrotoxic cardiomyopathy Russia. Cardiomyopathies, Russia, pp. 553-581.

12. Faizel O, Michael DG, Michael CS, Jayne AF (2002) Cardiac dysrhythmias and thyroid dysfunction-The hidden menace? J Clin Endocrinol Metab 87(3): 963-967.

13. Ademolu AB, Ademolu AO, Ogbera AO, Fasanmade O (2014) Hypoglycaemia in ikorodu. Journal of Asian Health, California, USA.

14. Sibel E, Arrigo FC (2013) Hyperthyroidism and cardiovascular complications: a narrative review on the basis of pathophysiology. Arch Med Sci 9(5): 944-952.

15. Bernadette B (2012) Mechanisms in endocrinology: heart failure and thyroid dysfunction. Eur J Endocrinol 167(5): 609-618.

16. Ira MG, James RS (2014) Thyroid and the heart. Am J Med 127(8): 691698.

17. Keniel P, Sushee G, Bassam O, Mustafa AG, Christopher M, et al. (2017) Thyrotoxic valvulopathy: case report and review of the literature. Cardiol Res 8(3): 134-138.

18. Silvia SP, Eider PC, Juan CG (2012) Management of subclinical hyperthyroidism. Int J Endocrinol Metab 10(2): 490-496. 